\title{
La necesaria discusión teórica marxista del Estado en el proceso de formación profesional en Trabajo Social
}

\section{The Marxist theoretical discussion of the State in the process of professional training in Social Work}

\author{
Adriana Monge Arias ${ }^{1}$
}

Fecha de recepción: 9-4-2020

Fecha de aceptación: 8-5-2021

\begin{abstract}
Resumen
El presente artículo pretende exponer la importancia que posee para la formación del Trabajo Social el estudio, análisis y comprensión del Estado desde los aportes del marxismo. Por ello, tiene como objetivo evidenciar a nivel teórico la relevancia de este pensamiento para la profesión en su praxis a través de las políticas sociales implementadas por el aparato estatal.

En esta investigación se obtuvo, como uno de sus productos, una síntesis de los programas impartidos en la carrera de Trabajo Social en el cuarto año, o III nivel (último año para obtener el título de bachillerato) vinculado a un análisis documental de datos relevantes para comprender el origen y desarrollo que ha tenido la formación en esta profesión en el espacio regional. Por tanto, se tiene como punto de partida que la profesión del Trabajo Social por medio de una praxis crítica, puede lograr avances en los procesos que busquen cierto bienestar de la clase trabajadora, masas populares y grupos oprimidos en el capitalismo. Para ello, es fundamental el conocimiento sobre la forma Estado capitalista y su funcionamiento, a partir de los aportes del marxismo hacia una teoría del Estado. Es decir, la necesaria comprensión a partir de ésta matriz teórica-metodológica teniendo como punto de partida la particularización de la profesión en el espacio estatal como producto de la sociedad burguesa.
\end{abstract}

Palabras clave: Estado, marxismo, capitalismo, Trabajo Social, política social.

\begin{abstract}
This article aims to expose the importance of the study, analysis and understanding of the State from the contributions of Marxism for the formation of Social Work. Therefore, its objective is to highlight the relevance of this thought for the profession in its practice through the social policies implemented by the state apparatus.

In this research, one of its products obtained was a synthesis of the programs taught in the Career at the fourth year level, related to a documentary analysis of relevant data in order to understand the origin and development of training in this discipline in the regional space. Social Work, through a critical praxis, can achieve advances in the processes that seek a certain welfare of the exploited classes and oppressed sectors in capitalism. For this porpose, knowledge about the form and functioning of the capitalist state is fundamental, based on the contributions of Marxism to a theory of the state.
\end{abstract}

Keywords: State, marxism, capitalism, Social Work, social policy

\footnotetext{
1 Licenciada en Trabajo Social, docente de la Universidad de Costa Rica, Sede Occidente, Costa Rica. Correo electrónico: monge.adriana@ gmail.com
} 
El sistema

Plan de exterminio: arrasar la hierba, arrancar de raíz hasta la última plantita todavía viva, regar la tierra con sal. Después, matar la memoria de la hierba. Para colonizar las conciencas, suprimirlas; para suprimirlas, vaciarlas de pasado. Aniquilar todo testimonio de que en la comarca hubo algo más que silencio, cárceles y tumbas.

Está prohibido recordar...

(Eduardo Galeano. Días y noches de amor y de guerra)

\section{Introducción}

Lo que se busca con el artículo es exponer la importancia, en un nivel teórico (categorías y conceptos) del análisis, que tiene para la formación en Trabajo Social el estudio y comprensión del Estado desde los aportes del marxismo. Esto con el objetivo de evidenciar la relevancia de este pensamiento para la disciplina en su ejercicio profesional, a pesar de encontrarnos en un periodo sociohistórico en el cual se le ha querido desplazar y suplantar por teorías posmodernas emergentes, que pretenden, al igual que el neoliberalismo, ocultar y descartar el marxismo, siendo catalogado como un "anacronismo", por tanto no vigente para el estudio de la realidad. Ya que, la lucha por la superación del capitalismo, parece, según estas nuevas tendencias, se ha acabado y no es posible optar por un proyecto común, donde el elemento de clase sea el punto de partida articulador de las heterogéneas formas de opresión.

Para el Trabajo Social el estudio del Estado de tipo capitalista ${ }^{2}$ como aparato de dominación, legitimación, consenso, coerción y "voz hegemónica" es fundamental, ya que es a partir de esta organización política central que se ejecutan las diversas formas de intervenir en las contradicciones del capitalismo. Estas últimas consideradas necesarias de control y contención dependiendo del periodo sociohistórico en el cual convergen las diferentes luchas sociales y políticas.

Es por ello que, comprender y analizar el Estado se vuelve para la profesión un elemento medular. Siendo un momento-espacio del proceso de acumulación del capital, debe mantener el orden, la cohesión, la legitimación, hegemonía y crear condiciones para la relación social capitalista, de la cual es parte. Esto a partir de su incidencia en las diferentes formas de organización del capital a nivel económico, político, cultural e ideológico, según sean las necesidades e intereses que se enfrenten de acuerdo con las condiciones del proceso de acumulación. Así, a través de su discurso y práctica incide en las heterogéneas manifestaciones de la cuestión social, desarrollando e implementando políticas públicas dirigidas hacia la atención de la desigualdad, la pobreza, la opresión de género, raza, etnia, la violencia, entre otros.

Siendo las políticas públicas, en lo social, el espacio central del Trabajo Social, es necesario comprenderlas desde una visión de la totalidad social, es decir son una parte de un entramado de relaciones sociales. En esta complejidad de relaciones sociales, el Estado es la organización políticacentral- de la relación social capitalista. Por tanto, al igual que las otras formas de organización del capital aparece separada del proceso de producción y reproducción del capital, y así se presenta como aparato neutral ante la sociedad, ocultando su origen y fetichizando las relaciones de explotación y opresión por medio de la figura de ciudadanía que se convierte en la mediadora en el mercado para la venta-compra de la fuerza de trabajo.

La institucionalidad formal de lo social se configura como una herramienta estatal capitalista, pretendiendo gestionar las contradicciones surgidas del proceso de

\footnotetext{
2 De acuerdo a lo planteado por Jessop (2017) el análisis del Estado implica diferentes niveles. En este caso se parte de una interpretación específica, ya que se tiene como base el Estado como tipo capitalista y las diferentes teorizaciones marxistas o ideas que desde este pensamiento se articulan para comprender la forma en que se puede aprehender el Estado. Es decir, se trata de una teoría del Estado desarrollada a partir de las propuestas del marxismo en sus diferentes enfoques. Por ello, siguiendo el mismo autor, se plantea una jerarquía de conceptos pasando a comprender la tipología de los Estados en relación a determinadas formaciones sociales, esto refiere a los modos de producción dominantes. Estar en el nivel de tipo de Estado, asumiendo una forma particular, permite avanzar hacia el funcionamiento específico en las formaciones sociales, en este caso, las sociedades capitalistas. Nivel en el cual se pretendió analizar la propuesta teórica marxista en relación con el Trabajo Social.
} 
producción y acumulación de la riqueza. Es el espacio desde donde la burguesía y sus distintas fracciones -en conflicto- buscan hegemonizar su proyecto de sociedad en puja con la clase trabajadora, masas populares y grupos oprimidos. Comprendiendo que el aparato estatal, es la relación social capitalista concretada en una estructura que de parte a parte se encuentra transversada por las luchas sociales y políticas, en un accionar contradictorio, expresando la contradicción propia del capital.

De este modo, comprender su estructura y funcionamiento, agentes y accionar es necesario para la profesión del Trabajo Social, en su proceso de formación académica. Profesionales que serán parte de la fuerza de trabajo contratada, para que por medio de su accionar implementen las políticas sociales desde el espacio estatal, es decir actúen en esa estructura de poder, "consenso", coerción y dominación.

Por ello, se parte desde la matriz teórico-metodológica marxista comprendiendo que el surgimiento de la profesión del Trabajo Social en la sociedad capitalista, está en relación con la atención de la cuestión social, mediante la intervención del Estado en la regulación de los procesos de reproducción social, y a la vez se es producto de la división social y técnica del trabajo (Iamamoto, 2001). Es decir, se propone reconocer la importancia que adquiere una base de pensamiento para acercarse a describir la relación con ejercicio profesional en lo concreto, teniendo claro el ámbito central del ejercicio profesional, la cuestión social (Guerra, 2015), en un plano de lo abstracto. Por tanto, no se busca "medir el impacto" en el estudiantado, sino dar una discusión teórica de las diferentes tendencias del marxismo sobre el Estado. Para esto último, y poder delimitar los autores y autoras, así como las tendencias, se retoman los programas de los cursos del estado desarrollados en la carrera de Trabajo Social, de la Sede de Occidente 3 .

\section{Los autores, autoras y tendencias: carrera de Trabajo Social, Sede de Occidente}

En los diferentes programas de Teoría del Estado de cuarto año de la carrera de Trabajo Social se van incorporando tendencias y autores marxistas (según el periodo). A continuación, se exponen los autores utilizados - o incorporados en su bibliografía- en diferentes momentos, para luego pasar a la exposición teórica de los aportes de cada uno, según los rasgos fundamentales del Estado capitalista por estudiar desde el marxismo.

Al iniciar la carrera de Trabajo Social en la Sede de Occidente, como carrera propia, lo hace a través de la organización de su malla curricular bajo la modalidad de 'taller', la cual consistía en articular ejes interdisciplinarios centrados en desarrollar diferentes temáticas relacionadas sobre una base. De esta manera, conformaban los talleres distintas disciplinas: Trabajo Social, Sociología, Antropología, Filosofía y Psicología. Cada una de ellas se centraba en un área de tal forma que brindara insumos teórico-metodológicos para comprender, fundamentalmente la relación entre el Trabajo Social, políticas públicas, el Estado y el capitalismo. Durante los setenta y ochenta la visión sobre el Estado combina tendencias, de Carlos Marx, Federico Engels, Vladimir Lenin, Louis Althusser, Nicos Poulantzas, Antonio Gramsci, Elmar Altvater, Joachim Hirsch y Ralp Miliband. En los noventa hay pocos programas registrados sobre el curso de Teoría del Estado, solamente se cuenta con dos (1990 y 1992), en el que la base de la discusión gira sobre Carlos Marx, Ferderico Engels Nicos Poulantzas, Elmar Altvater y Antonio Gramsci y se incorpora a Max Weber.

Para el siglo XXI, hay un cambio radical en la forma de enseñanza de la teoría del estado, con dos momentos diferentes: hasta el 2009 se desplaza la base marxista y se estudia más desde lo denominado, los paradigmas de las Ciencias Sociales. Para el caso del marxismo, se hace

3 Los programas de cursos que se analizan corresponden al cuarto año, y para este artículo se hace referencia a los que corresponde a Teoría del Estado, impartido durante el I ciclo. En la revisión se evidencia que existen periodos donde la carrera no los registró Estos datos empíricos son tomados como ejemplos breves, para desarrollar el enfoque teórico que es colocado en ese momento en la carrera, como parte de la formación. Un punto de partida para insertarse en la discusión abstracta del pensamiento marxista y su relación con el Trabajo Social. 
uso de Elmar Altvater, Nicos Poulantzas y Federico Engels -aparecen en su bibliografía -. Del 2009 al 2011, es un proceso de transición, con la excepción del 2010, (que siguió la tendencia de los programas hasta el 2008), se empieza dejar de lado la tendencia de análisis basada en paradigmas. Nuevamente se hace uso de Antonio Gramsci, se mantiene Elmar Altvater y aparece Tilman Evers para comprender el estado capitalista periférico. En el 2011, regresa Louis Althusser y Ralp Miliband. En el 2014, se vuelve a integrar a Poulantzas (no incorporado durante 2009, 2011, 2012 y 2013). Para el 2016, la propuesta teórico-metodológica de Luis Vitale, es utilizada para explicar el origen del Estado en América Latina. Y es en el 2018, que se incluye como parte de la teoría derivacionista a John Holloway y se vuelve a retomar a Joachim Hirsch en la bibliografía. Es importante agregar, que en esta modificación el curso se centra en estudiar el Estado en relación con las políticas públicas, cambiando su nombre a Teoría del Estado y Políticas Públicas ${ }^{4}$.

\section{El Estado: la relación social capitalista particularizada a nivel político}

El Estado moderno ha sido estudiado desde diferentes posiciones teóricas, se discute su origen, forma y carácter que van generando una convergencia de conocimientos sobre su poder, naturaleza, funciones y su relación con lo económico, lo cultural e ideológico, es decir la relación entre la sociedad y el estado.

El marxismo es una matriz teórica-metodológica y a la vez una propuesta política ${ }^{5}$ que permite comprender los diferentes fenómenos desde una visión de la totalidad social, lo que ayuda a explicar las partes en relación, jerarquizadas, estructuradas y en devenir. Avanzando en una concepción del Estado no de forma estática, subjetivista, aislada, o desarticulada de la sociedad sino, por el contrario, partir de una posición dialéctica que conlleva a contextualizar y desarrollar los procesos que le dan base y sobre los cuales luego el Estado incide una vez que se estructura.

La teoría marxista del Estado la podemos encontrar desde sus clásicos, los cuales generaron una serie de aportes que poco a poco dieron herramientas teóricas para la discusión en la época contemporánea. Carlos Marx, Federico Engels, Vladimir Lenin, Rosa Luxemburgo y Antonio Gramsci, desarrollaron diferentes elementos en relación con el contexto histórico en el que se encontraban. Sus argumentaciones han sido ampliadas, discutidas, y articuladas, esto según las tendencias que se generan dentro del mismo marxismo.

A nivel general, desde el marxismo, el Estado capitalista es un fenómeno social, resultado de la organización social humana político-administrativa institucional, se consolida como una maquinaria centralizada de poder clasista. Su poder no es neutral, sino que es un espacio de organización política del capital, comprendido como relación social contradictoria.

Se trata de una relación social estructurada que toma accionar a través de un cúmulo de instituciones, distribuidos en aparatos donde buscan anudar su poder las clases burguesas en la necesaria organización política para poder incidir a nivel general en las condiciones sociohistóricas, pugnando también la clase trabajadora, masas populares y grupos oprimidos en sus demandas hacia el Estado por ser parte de las políticas sociales. Es decir, es un movimiento de acción y reacción de las diferentes dimensiones que se relacionan en la totalidad social, a partir del proceso de acumulación del capital.

Ahora, el desarrollo de los contenidos del marxismo se va enfocando en diferentes elementos en la carrera de Trabajo

4 Una vez modificado el programa a partir del siglo XXI, donde se combina el estudio del Estado con las Políticas Públicas, la discusión teórica del marxismo se hace limitando los autores, y tendencias. Del 2011 al 2016 se hace uso del texto de Josep Picó (1999), para sintetizar la discusión marxista, restándole solidez al desarrollo de la teorización a partir de sus exponentes originales.

5 Se retoma lo planteado por Ayala (2016) para hacer referencia a dos elementos que componen al marxismo, se lo concibe como una teoría de la totalidad social (multidimensional, estructurada, jerarquizada y en movimiento) fundada en un análisis de economía política., un análisis crítico del capitalismo en el marco de una teoría materialista de lo histórico-social. Segundo, el marxismo es un marco teórico - metodológico para el conocimiento (para construir y revisar los instrumentos conceptuales de captación) y el examen crítico de lo real; una teoría que busca fundar racionalmente la acción, que es una praxis, pero una transformadora que quiere ser consciente y racional (p. 8). 
Social, de la Sede de Occidente. Durante los ochenta es visto el aparato estatal desde, una idea central, la metáfora del edificio planteada por Marx en el texto Contribución a la Crítica de la Economía Política, en el prólogo de 1859, y los argumentos desarrollados en la Ideología Alemana junto con Engels, para luego ser retomada por Althusser (1980) en su libro Ideología y Aparatos Ideológicos del Estado, continuado por Poulantzas (1972 y 1977) en una primera etapa, quien luego haría fuertes críticas a esta forma de explicar el Estado.

En el prólogo del texto de Contribución a la Crítica de la Economía Política, Marx (1859) plantea la discusión de la relación dialéctica entre lo económico, lo político-jurídico e ideológico, pero no en la lógica e historicidad de un economicismo, como lo han colocado algunas tendencias marxistas, y sobre todo el estalinismo, sino partiendo de la totalidad dialéctica, comprendiendo que el punto de partida son las condiciones sociomateriales del proceso sociohistórico concreto, para adentrarse en la anatomía de la sociedad, de manera que:

En la producción social de su existencia los hombres establecen determinadas relaciones necesarias e independientes de su voluntad, relaciones de producción que corresponden a un determinado estadio evolutivo de sus fuerzas productivas materiales. La totalidad de esas relaciones de producción constituye la estructura económica de la sociedad, la base real sobre la cual se alza un edificio jurídico y político, y la cual corresponden determinadas formas de conciencia social (Marx, 2008, p.4)

En el caso de Althusser (1980), esta interpretación metafórica de Marx es retomada para explicar la forma en que el Estado se sostiene sobre la base de la economía, siendo protagonista en el proceso de reproducción ideológica y represiva del individuo necesario para la producción capitalista, por tanto, indica que:

Cualquiera puede convencerse fácilmente de que representar la estructura de toda sociedad como edificio compuesto por una base (infraestructura) sobre la que se levantan los dos "pisos" de la superestructura constituye una metáfora, más exactamente una metáfora espacial: la de una tópica. Como toda metáfora esta sugiere, hace ver alguna cosa ¿Qué cosa? Que los pisos superiores no podrían "sostenerse" (en el aire) por sí solos si no se apoyaran precisamente sobre su base (p. 17)

En el programa de la carrera de Trabajo Social de 1980, el Taller III 1, en el área de Sociología, indica que se buscará analizar los conceptos generales básicos sobre el Estado, partiendo de la relación de los elementos de la superestructura jurídico-política con la base económica ${ }^{6}$. Lo cual permite comprender la influencia de la perspectiva estructuralista, que tiene como referente Althusser y que luego producto de la discusión entre Poulantzas y Miliband respecto al Estado durante la década de los setenta, tomará auge como una tendencia desde el marxismo para explicar el aparato estatal moderno.

Lo anterior ha traído fuertes discusiones, porque se trata de asemejar esta postura con un economicismo, lo cual oculta la posición de Marx respecto la relación entre las diferentes partes que se relacionan en una totalidad social, en este caso, la sociedad burguesa, siendo su visión la de explicar la relación entre lo económico y lo político como dos fuerzas desiguales que se combinan y separan a la vez, porque son parte de la unidad de la relación social capitalista. De una parte, el movimiento económico que se imprime siempre en términos generales, y de otra el poder político. Es decir, lo económico se halla también sujeto a las repercusiones del movimiento político siendo parte de la relación social capitalista, por tanto es un proceso co-constitutivo de acciones y reacciones.

Tal y como lo plantea Engels (1975) en el texto de Ludwig Feuerbach y el fin de la filosofía clásica alemana, se trata de explicar las fuerzas motrices fundamentales, buscando qué mueven las masas, los bloques, los colectivos, clases enteras, no al sujeto aislado de este concreto particular. Lo que lleva a entender las acciones continuas que generan grandes cambios sociohistóricos, determinando cuáles son los móviles de los móviles superando la apariencia de las casualidades, de la suerte o el azar. 
Es decir, las voluntades de las personas hacen la historia, mueven las estructuras, la acción política de los colectivos, grupos o masas inciden sobre los procesos generales y particulares de la historia, pero en condiciones estructuradas que estructuran las prácticas generando reacciones en los diferentes espacios de organización del capital, por tanto como lo explica Marx (2012) en el Dieciocho Brumario de Luis Bonaparte: "Los hombres [las personas] hacen su propia historia, pero no la hacen a su voluntad, bajo condiciones elegidas por ellos [y ellas] mismos, sino bajo condiciones directamente existentes, dadas y heredadas" (p.33).

Se ocupa, por ello, el marxismo, de la naturaleza del poder del Estado y de la distinción del Estado moderno en cuanto producto de la sociedad civil.

Con el surgimiento del capitalismo, la modernidad cobra auge al consolidarse un terreno que le permite su desenvolvimiento desde la dirección de la clase dominante emergente, la burguesía, tal y como es planteado en la Ideología Alemana7. Esto va consolidando una nueva forma de organización estatal que no se trata de un simple reflejo del nuevo modo de producción. No hay una transformación política instantánea. Por ejemplo, en Europa el orden estatal siguió siendo feudal, mientras la sociedad se hacía cada vez más burguesa (Engels, 2014).

La relación entre lo económico y lo político no es un automatismo, ya que se trata de procesos de cambios donde prevalecen las relaciones y contradicciones de clase:

Si nos detenemos a indagar esto veremos que en la historia moderna la voluntad del estado obedece, en general, a las necesidades variables de la sociedad civil $^{8}$, a la supremacía de tal o cual clase, y, en última instancia, al desarrollo de las fuerzas productivas y de las condiciones de intercambio. (Engels, 1975, p.58)
Sin embargo, Engels aclara que este condicionamiento general es concreto y dialéctico no formalista y abstracto, es decir, se expresa y concretiza en cada realidad, espacio y tiempo de acuerdo con la combinación de los diferentes elementos que se desarrollen y articulen conforme al proceso de acumulación del capitalismo y las luchas sociales que emergen producto de sus contradicciones.

Por ello, desde el marxismo se comprende que el Estado se explica en relación con la sociedad, no es una "cosa", un afuera que por sí mismo se pueda entender, es un producto que luego incide sobre las relaciones y estructuras que le dieron origen y transformaron. Por ello, se encuentra como una parte de esa totalidad, que en nuestro contexto refiere al capitalismo con sus diferentes contradicciones. Como lo plantean Marx y Engels (2014):

La organización social y el Estado brotan constantemente del proceso de vida de determinados individuos; pero de estos individuos, no como puedan presentarse ante la imaginación propia o ajena, sino tal y como realmente son; es decir, tal y como actúan y como producen materialmente $\mathrm{y}$, por tanto, tal y como desarrollan sus actividades bajo determinados límites, premisas y condiciones materiales, independientes de su voluntad (p. 21)

Con el Estado moderno surge un aparato y poder capitalista, que a diferencia de las otras formas de organización política, se va a encargar de colocarse como el centro del interés general, desde una apariencia -forma- de neutralidad, que basado en la democracia burguesa desarrolla una legitimidad que lo coloca como el que puede tomar las grandes decisiones en nombre del pueblo, partiendo de una igualdad formal, en el nivel de lo político. Se presenta por tanto, como separado de lo económico y, por ende, alejado de cualquier incidencia de un interés particular. Siendo el triunfo del control de la hegemonía exclusiva del poder político de parte de

\footnotetext{
7 La sociedad civil abarca todo el intercambio material de los individuos-individuas, en una determinada fase de desarrollo de las fuerzas productivas. Abarca toda la vida comercial e industrial de una fase y, en este sentido, trasciende de los límites del Estado y de la nación, si bien, por otra parte, tiene necesariamente que hacerse valer al exterior como nacionalidad y, vista hacia el interior, como Estado...la sociedad civil en cuanto tal, solo se desarrolla con la burguesía (Marx y Engels, 2014, p. 30)
}

8 Aquí Engels utiliza la categoría sociedad civil como el espacio donde convergen las relaciones económicas 
la burguesía que entrará en contradicción con la clase trabajadora y sectores oprimidos que irán pugnando por tener incidencia en el poder político.

\subsection{Estado y su carácter clasista}

En el marxismo hay un elemento central, es asignarle un rasgo esencial al Estado, una naturaleza de clase. Y esto tiene sus matices de acuerdo a la tendencia teórica sobre la cual se analice el aparato estatal. Esta idea central es la que se mantiene como base en los programas de teoría del Estado en la carrera de Trabajo Social - según los que se lograron encontrar - hasta el 2000. Se estudiaba exclusivamente tomando como base este postulado, es decir la discusión tenía como punto de partida y de llegada entender el Estado capitalista como instrumento de poder, hegemonía y dominación política (Programa Taller IIIA, área Teoría del Estado, 1982) de acuerdo al margen de revisión que permitió la investigación, a otras tendencias contrarias al marxismo. El Programa de 1990 y 1992 Teoría y Metodología del Trabajo Social III, área de Teoría del Estado indica en sus contenidos el estudio del Estado como estructura de poder y de dominación de las relaciones sociales, centrando el análisis en la problemática de la sociedad civil y sociedad política ${ }^{10}$. Elementos determinados por Gramsci que van a hacer retomados por Althusser.

Para Althusser (1980), partiendo de su texto Ideología y Aparatos Ideológicos del Estado, la naturaleza de clase del Estado se encuentra en conformar parte de la superestructura jurídico-política e ideológica que se encuentra condicionada por la infraestructura económica, en este caso capitalista. Así, el aparato estatal dividido en aparatos ideológicos y aparato represivo se encarga de reproducir la fuerza de trabajo por medio de la ideología y la represión, donde:

Ellos [se refiere a los aparatos ideológicos], en efecto, aseguran en gran parte, tras el "escudo" del aparato represivo de Estado, la reproducción misma de las relaciones de producción. Es aquí donde interviene masivamente el rol de la ideología dominante, la de la clase dominante, que tiene el poder de Estado. A través de la ideología dominante se asegura la "armonía" (a veces estridente) entre el aparato represivo de Estado y los aparatos ideológicos de Estado y entre diferentes aparatos ideológicos (p.37)

Está marcado por su función de representar y preservar los intereses de la clase dominante, de acuerdo con el planteamiento del autor, pero esto no es un automatismo como a veces no parece quedar claro en Althusser (1980), ya que cuando hace referencia a la lucha de clases no queda explícita la relación con las ideas centrales del texto y por ello, prevalece más una visión estructuralista.

Conforme avanza el capitalismo y con ello su correlato inherente, la luchas sociales, el Estado va ampliando o desarrollando nuevas funciones que debe integrar, aunque de forma subordinada ciertos intereses de la clase trabajadora, masas populares y grupos oprimidos esto no quiere decir que sea un espacio neutro, donde todos los actores tienen iguales condiciones para incidir en la toma de las grandes decisiones, sino que se complejiza el accionar estatal y se convierte en un campo de lucha que mantiene el orden general al ser el factor de cohesión. Esto último, en Poulantzas (1972 y 1977) ${ }^{11}$, es un elemento central para comprender la no neutralidad del Estado, es decir su naturaleza de clase, ya que es el organizador de los distintos niveles de las formaciones sociales, al conformar parte de la instancia política, tiene una función global: asegurar la cohesión y por tanto permitir que la acumulación de capital se pueda desarrollar libremente.

De acuerdo con la idea anterior, el autor continúa con una línea estructuralista, para luego ampliar su propuesta sobre el aparato estatal visto como la condensación de fuerzas de clases y fracciones de clases contradictorias que se estructuran en todos y cada uno de los espacios

\footnotetext{
$9 \quad$ En el programa de 1980 se establece como uno de sus objetivos generales: Analizar el carácter históricamente clasista del Estado (Programa Taller IIIA, área de Sociología, 1980)

10 Incorporando también a Max Weber

11 Nicos Poulantzas es el autor que más recurrencia tiene en la bibliografía de los programas revisados.
} 
estatales (se anudan en el aparato del Estado las relaciones contradictorias de las clases y fracciones dominantes). Por tanto, es un campo de lucha, que articula y organiza la clase dominante, del bloque en el poder y desarticula la clase trabajadora, masas populares y grupos oprimidos desde su carácter estructural de clase no neutral Según Poulantzas (1983) el Estado capitalista debe ser considerado "como una relación, más exactamente como una condensación material de una relación de fuerzas entre clases y fracciones de clases, tal como se expresa, siempre de forma específica, en el seno del Estado" (p.154).

Desde otra perspectiva, o haciendo énfasis en los vínculos entre la clase burguesa y las élites estatales, en Miliband (1978), esas relaciones de fuerza de las clases se dan en una competencia imperfecta ya que:

la igualdad política, salvo formalmente, es imposible en las condiciones del capitalismo avanzado. La vida económica no puede divorciarse de la vida política. El poder económico desigual, de magnitud y de carácter de las sociedades capitalistas avanzadas, produce por necesidad una desigualdad política más o menos grande, independientemente de lo que pueda decir la Constitución (p.255)

La propuesta de Miliband (1978) ${ }^{12}$ a diferencia de Althusser (1980) y Poulantzas (1977, 1979 y 1983), se centra en comprender la no neutralidad a partir de la relación de las élites estatales con las élites económicas (entre quienes agencian el Estado y los capitalistas). Para el autor, el aparato estatal es clasista en el sentido que resguarda al igual que la sociedad de clases, una forma de estratificación interna permitiendo que los "hombres de negocios" sean los que puedan tener acceso a la toma de las grandes decisiones. Ya sea de manera indirecta o directa inciden en lo político, y esto se debe a la meritocracia que al actuar en una sociedad dividida en clases prevalecen los privilegios y el control de los puestos estatales de parte de las élites económicas, las cuales tienen un origen de clase, mantienen vínculos familiares y de amistad y son las que cuentan con las mejores oportunidades educativas necesarias para ser parte de la selección para ocupar los lugares del Estado decisores de la política nacional e internacional.

Es decir, para Miliband (1978), el estudio clasista del Estado se centra en explicar quiénes ocupan los principales puestos de toma de decisiones en el aparato estatal, es más la relación entre la élite estatal y élites económicas, los vínculos a partir de los cuales instrumentaliza la clase capitalista el aparato estatal (sin ser un simple instrumento para Miliband), es decir sus prácticas $\mathrm{y}$ acciones, elemento fundamental para el ejercicio profesional del Trabajo Social al comprender "quiénes mueven los hilos de las políticas sociales” (Pastorini, 2000). Al estar centrado en la discusión de identificar cómo la clase burguesa coloniza los espacios estatales para transformarse en la clase imperante, la que tiene el poder económico y político, y con ello comprender cómo llegan sus demandas al sistema estatal, en una competencia imperfecta frente a los otros actores, la clase trabajadora, al tener colonizado los principales espacios del sistema estatal donde se toman las grandes decisiones, como las políticas sociales.

Distinto a lo planteado por Althusser (1980) ${ }^{13}$, Miliband (1978) y Poulantzas (1972, 1977 y 1983)

12 Ralp Miliband toma relevancia en el estudio del Estado a partir del 2011 periodo donde la carrera de Trabajo Social asume el curso, como parte de los que serán impartidos desde el equipo de docentes de Trabajo Social. Con esto, sufre modificaciones importantes, lo cual conlleva a comprender mejor la relación entre el Estado, cuestión social, las políticas sociales y el Trabajo Social, ya que es un acercamiento a identificar quiénes son los que "mueven los hilos" de la política social.

13 Para la propuesta derivacionista el Estado no se explica desde el esquema base/superestructura, donde el Estado sería una derivación de lo económico. Por el contrario, para estos autores y autoras, lo político y lo económico son formas derivadas de las relaciones sociales capitalistas. Por tanto, sería una superación de la visión dualista de Althusser, al plantear ambas como parte de la unidad-separación de las relaciones capitalistas. 
los derivacionistas ${ }^{14}$ determinan que el origen clasista del Estado está en ser una forma política de las relaciones sociales capitalistas, colocándose como forma ajena o distante a los modos de existencia de ésas relaciones sociales, es decir su aparición como neutral, en la separación entre lo económico y lo político fundada en la separación de los productores directos de los medios de producción, propio del proceso lógico e histórico de la acumulación del capital (que se sostiene en esta separación, la producción privada y el intercambio mercantil (Hirsh, 2007)). Es por ello, que se transforma en el espacio a través del cual se pueden tomar grandes decisiones, sin que se considere como un interés particular de clase, porque su presentación ahistórica, y como instancia separada (particularización política) de la sociedad y las clases sociales lo lleva a ser una especie de fetiche, que cobra distancia propia, sin tener ningún tipo de relación con las condiciones concretas y materiales, lejos de las luchas sociales y contradicciones del capitalismo (al decir de Engels, 1970), externo y al lado de las relaciones de producción y explotación, por tanto de la relación capital-trabajo). De esta manera, se trata de la consolidación de un interés particular de clase como el interés general, cobrando el Estado capitalista una forma propia e independiente, separada de los reales intereses particulares y colectivos, es el dominio del poder político (Marx y Engels, 2014).

Esta condición de aparecer como neutral en el capitalismo, es propia de la lógica y de y del proceso histórico del capitalismo, y es aquí donde las tendencias derivacionistas dan su punto central en reconocer el carácter clasista del Estado, pero a partir de la derivación del proceso de acumulación, y por ello su planteamiento es distinto y están basados en El Capital, la visión hace referencia al concepto de apariencia-relacionalidad (separación - unidad de lo económico y lo político; del Estado y la sociedad) del Estado, es la forma política que toma el mismo nivel que la forma valor, al ser una forma particularizada del conjunto de relaciones sociales capitalistas (Holloway, 2017), diferencia fundamental con Poulantzas desde su visión estructuralista enfocado en el aparato estatal ${ }^{15}$. Tanto Hirsch, Altvater, como Holloway, entre otros, con sus diferencias y debates, plantean que el Estado es una forma política de la relación base de dominación, es la forma de aparecer la dominación política del capital. Por tanto:

el Estado, tal y como existe hoy en día es un producto histórico, una forma históricamente determinada de la organización de la dominación; y que, siendo histórica, tiene sus fundamentos tanto en la forma de producción y reproducción social que caracteriza la relación burguesa de producción como en las relaciones de clase resultantes de ella. (Hirsch, 2017, p.510)

De esta manera adopta en la sociedad burguesa, una característica fundamental, la forma política impersonal por encima de la sociedad y de las clases sociales (Hirsch, 2007 y 2017; Holloway, 1980, 1994 y 2017). Y por tanto, es una forma fetichizada de la relación social capitalista

14 A diferencia del debate alemán, que se centra en el análisis de la interrelación, de la unidad en la separación de las diferentes esferas, e insiste en que este es el centro de un entendimiento materialista de lo político, tanto Miliband como Paulantzas se centran en lo político como un objeto de estudio autónomo argumentando, al menos implícitamente, que un reconocimiento de la especificidad de lo político es una precondición necesaria para la elaboración de conceptos científicos (Holloway y Picciotto, 2017, p. 84). El pensamiento derivacionista propone una teoría materialista del Estado a partir del desarrollo de los conceptos de El Capital.

15 Agradezco al primer par revisor la recomendación dada sobre la importancia de determinar claramente la diferencia entre la tendencia derivacionista y la propuesta de Poulantzas. En palabras de Bonnet (2016): En este sentido, hay que distinguir entre el Estado como forma, es decir como modo de existencia de las relaciones sociales capitalistas en tanto de relaciones de dominación, diferenciando el modo de existencia de esas mismas relaciones sociales capitalistas en tanto, relaciones de explotación, y el Estado como aparato, esto es, como institucionalización de esa existencia particularizada de las relaciones de dominación. Y la diferencia tiene implicancias. El carácter capitalista del Estado no depende de esas relaciones de fuerza particulares entre clases y fracciones de clases que cristalizan en su aparato, sino de su existencia misma como relación de dominación separada de las relaciones de explotación. El Estado capitalista, en consecuencia, no puede definirse a partir de su aparato, sino de su forma (p.3). Tanto en el primer Poulantzas, como en su segunda propuesta termina centrando su argumentación en el aparato del estado como materialización, que para los derivacionistas, significa una continuidad en la incomprensión de los modos de existencia de las relaciones sociales en el capitalismo, ya que conlleva a determinar que el carácter capitalista del Estado depende de las relaciones de fuerza que se materializan en su aparato (las correlaciones de fuerza condensadas), la particularización de lo político en la separación base entre los productores y los medios de producción pierde la especificidad capitalista, es decir su apariencia neutral. 
contradictoria, como lo es el capital, reproduciendo su lógica en tanto se reproduce a sí mismo como parte o momento que conlleva el proceso histórico de la acumulación del capital. La fetichización, se expresa en no aparecer como un aparato de dominación de clase, es como la característica fundamental, pero que es constantemente puesta en cuestionamiento, ya que:

Las formas fetichizadas en que aparece o se presenta la dominación capitalista nunca pueden ser una cubierta totalmente opaca que oculte por completo la explotación clasista a quienes a ella están sometidos. La aparente neutralidad y fragmentación de las formas, las desconexiones oscurecedoras, contradicen continuamente toda la experiencia que los trabajadores tienen de la opresión clasista. (Holloway, 1980, pp.14-15)

Ante estas formas fetichizadas, las interrogantes que se hace un autor como Holloway (2017) están referida a: ¿Qué es lo que permite que el Estado capitalista pueda aparecer como un aparato de poder público por encima de la sociedad, sin conexión evidente con el derecho de disposición de los medios de producción? ¿Por qué la dominación de clase reviste un rostro anónimamente político e impersonal en el Estado? Estas interrogantes son discutidas, a la vez haciendo una crítica a la tendencia estructuralista, política y la metáfora del edificio, así como la tendencia de ver la no neutralidad del Estado por sus funciones, alejándose Hirsh y Holloway de Altvater, y con ello aclaran que:

Derivar el estado del capital, entonces, no es derivar lo político de lo económico sino derivar la particularización de lo político y lo económico de la estructura básica de las relaciones de dominación...El estado es capitalista por su forma, no por lo que hace, no por las funciones que cumple. Es simplemente por ser una instancia separada del proceso de producción y explotación que el estado es capitalista. (Holloway, 2017, pp. 41-42)

Por ello, es un Estado que separa y fragmenta en su accionar en la sociedad, tal y como su lógica al ser una derivación política de la organización del capital en el proceso de acumulación. A diferencia de esto, Altvater coloca el acento en las funciones, siendo uno de los autores de esta tendencia que se ocupa de comprender la forma Estado en relación a sus funciones. Para el Trabajo Social, este planteamiento es importante, porque permite comprender parte del proceso en el que se desarrolla la profesión, entre las políticas sociales y las personas que las demandan. Siendo el autor, que por lo menos a nivel de bibliografía, ha estado presente desde los primeros programas hasta la actualidad, para el siglo XXI aparece directamente en el cronograma del 2009 y 2015.

Es decir, el Estado no solo mantiene una función de orden no neutral entre las contradicciones que produce el capitalismo en relación con las opresiones pre-existentes, sino que genera las condiciones generales que requiere el capital dependiendo del momento histórico en el que se encuentre el capitalismo. Por ello, se encarga de condicionar una serie de políticas públicas que busquen garantizar la acumulación ampliada del capital, que corresponde al interés general de las burguesías, aunque en lo concreto e inmediato pugnen por sus intereses particulares. Esta praxis se dirige a:

- La creación de las condiciones generales de producción, como por ejemplo infraestructura vial, política monetaria, fiscal, comercial, etc.

- La determinación y protección del sistema legal general en el que tienen lugar las relaciones de los sujetos legales de la sociedad capitalista.

- Le regulación entre el conflicto entre el trabajo asalariado y el capital. Esta función como se ha explicado se caracteriza por combinar la coerción y la coacción, la dominación y la dirección. Según sean los intereses y el nivel de avance de la lucha social.

- La protección del capital nacional total y su expansión en el mercado capitalista mundial. Su política exterior que va dirigida dependiendo del lugar que le corresponda en la división internacional del trabajo (Altvater, 1976) 
Además, para llevar a cabo estas funciones, tiene un elemento fundamental en el capitalismo, el monopolio de la violencia legítima. Una violencia que será ideologizada como la forma de mantener el orden y la paz ante las controversias que surjan por las diversas contradicciones que van emergiendo conforme se desarrolla el capitalismo. Por ello, el Estado, en el capitalismo se va convirtiendo en una inmensa y compleja máquina, que será un botín en las luchas sociales, las clases dominantes pugnarán por su control, como lo plantea Marx (2012), en el texto del Dieciocho Brumario de Luis Bonaparte, "los partidos, que pugnaban alternativamente por el poder [se refiere a las pugnas entre las clases dominantes y su temor al proletariado y masas populares de Francia 1848-1851] consideraban la toma de este monstruoso edificio estatal como el botín principal del vencedor" (p.159).

Se trata de una máquina de dominación clasista, una fuerza de represión según los planteamientos de Engels (2004). Es una institución de fuerza pública, que no es el pueblo armado, se desarrolla una fuerza policíaca que va a ser mantenida a través de los impuestos. Los impuestos le van a dar una herramienta a la burguesía para pagar los funcionarios y funcionarias que van a llevar a cabo las tareas de dominación.

Esta maquinaria de poder es revestida por la hegemonía o la violencia, a la vez, reviste la hegemonía, de acuerdo a Gramsci. Lo cual permite que ciertas ideas y un modo de vida se legitimen como las que buscan el "bienestar" de toda la población:

Las ideas de la clase dominante son las ideas dominantes en cada época; o, dicho, en otros términos, la clase que ejerce el poder material dominante en la sociedad es, al mismo tiempo, su poder espiritual dominante. La clase que tiene a su disposición los medios para la producción material dispone con ello, al mismo tiempo, de los medios para la producción espiritual, lo que hace que se le sometan, al propio tiempo, por término medio, las ideas de quienes carecen de los medios necesarios para producir espiritualmente. (Marx y Engels, 2014, p.39)
El Estado supone un poder público particular, separado del conjunto de la ciudadanía que lo compone. Se trata de una institucionalidad que se levanta sobre las personas, es colocado como una estructura (estructurada y estructurante) que garantiza un orden determinado en relación con intereses generales de clase, pero sin aparecer como tal, y tampoco actuar en función o como un simple instrumento de la clase dominante, ya que esto conllevaría a pensar como la socialdemocracia, solamente ocupando los principales puestos de tomas de decisiones en el Estado se puede transformar el capitalismo.

Por ello, la crítica marxista a la socialdemocracia en su proyecto gradual y por la vía de la institucionalidad para llevar a cabo las grandes transformaciones, las reformas que emergen o se van a originar producto de las luchas sociales derivadas del proceso de acumulación del capital, serán vistas, por tanto, como una forma de resolver de forma inmediata las contradicciones del mismo capitalismo.

Sin dejar de lado o, más bien retomando la crítica al reformismo de la socialdemocracia, Rosa Luxemburgo, aclara y afirma que, si bien las reformas son parte de la estrategia del capital ante el caos y el conflicto, estas son parte, también de las conquistas sociales que no deben de desecharse o dejar de pugnar por ellas, sino que:

La pelea de todos los días por las reformas, por una mejor situación de los trabajadores de este sistema, y la pugna por las instituciones democráticas, le permite a la socialdemocracia la única amanera de participar junto con el proletariado en la lucha de clases, y propugnar la meta final: la toma del poder político y la anulación del trabajo asalariado. Hay una unión indisoluble, para la Socialdemocracia, entre las reformas sociales y la revolución; esto es que la pelea por estas reformas es el medio, y su fin es la revolución social (Luxemburgo, 2001, p.15)

Esto supone al Trabajo Social como profesión que interviene en las necesidades de las poblaciones explotadas y oprimidas desde las políticas sociales, entra en una lucha por generar acciones que si bien son reformas, pueden 
y generan cierto bienestar, pero que a la vez mantiene y opera la relación social capitalista, de tal manera que contradictoriamente es parte de la reproducción de la desigualdad en sentido general al accionar su intervención desde el Estado. Su praxis desde el aparato estatal hace uso de las distintas formas de control, combinando la dimensión de violencia y hegemonía que lo caracteriza, como lo plantea Gramsci (1980). Es aquí donde uno de los aportes de Holloway (1980, 2017), se hace fundamental, en cuanto a la combinación del accionar de las personas profesionales en Trabajo Social como parte de la clase trabajadora que debe vender su fuerza de trabajo para su propia sobrevivencia, pero que desde un proyecto ético-político crítico buscaría como fin la transformación de la sociedad capitalista, sin embargo se encuentra mediado por el aparato estatal o las particularidades de la dimensión socio-institucional (Mallardi, 2014), ante esta contradicción ¿cómo podemos evitar lo que llamamos el síndrome de Penélope como trabajadores estatales, construimos el capitalismo durante el día como militantes, tratamos de desmantelarlo durante la noche? Dimos una respuesta en términos de distinción entre el aparato estatal y la forma estatal: aunque trabajamos dentro del aparato estatal: si hay posibilidades de ir contra la forma estatal, de romper con el estado como forma de las relaciones sociales, superando la separación entre el estado y la sociedad en nuestra práctica (p.44)

El autor Gramsci, fue fundamental durante los ochenta y noventa en los cursos del Estado, se deja de utilizar durante prácticamente la primera década del siglo XXI, es retomado en el 2009, 2011 y luego hasta el 2014. En el Programa del Taller III de 1980 aparece la categoría hegemonía en el área de Sociología, también en el de 1981, así como la diferencia entre sociedad civil y sociedad política, discusión retomada por el autor en la comprensión del Estado más que como una máquina de dominación clasista por el monopolio de la violencia. Para 1990 y 1992, en el Programa Teoría y Metodología del Trabajo Social III, en el área de Teoría del Estado la categoría bloque histórico, relación entre sociedad civil y sociedad política conforman parte del desarrollo para comprender la dominación en la reproducción social, sin colocar en los contenidos la discusión de hegemonía, pero apareciendo en diferentes autores, entre estos Gramsci, en la bibliografía. Por otra parte, si se retoma la categoría legitimidad del poder político, donde parece retomar a Weber.

La teorización sobre hegemonía debe ser base para el Trabajo Social, sobre todo al tratar de comprender las mediaciones que convergen en el ejercicio profesional. Se hace necesario el análisis de la forma en que en el capitalismo se da el proceso de reproducción social mediado por el "consenso", como una manera de practicar el poder las clases dominantes a nivel macroestructural y de la vida cotidiana.

Son ideas importantes para el Trabajo Social, ya que para Gramsci (1980), en el Estado se combina la función de dominación y dirección, se ocupa de cómo estos se articulan para converger en lo que va a teorizar como hegemonía, por ello desarrolla una serie de categorías que ayudan a ampliar la manera en cómo las clases dominantes logran encubrir la coerción a través del consenso.

Las clases dominantes consolidan una hegemonía (Gramsci, 1980), que operan desde el Estado, es decir, a través de la imposición de una visión de mundo, un sentido común, una filosofía, una moral, las costumbres, la estructura sociocultural de una formación social que pretende reproducir sus intereses. Para ello, utilizan o funcionalizan diferentes organizaciones, instituciones y aparatos que actúan desde lo que denomina la sociedad civil, siendo este el espacio donde se ve reflejado las complejas relaciones ideológicas, culturales y morales que rigen en una sociedad determinada.

En Gramsci el Estado no deja de ser el aparato represivo que desde Marx, Engels, Lenin se teoriza, por el contrario se trata de evidenciar el control cultural que reviste la coerción y que lo hace desde instituciones como la escuela, la iglesia, el partido, el sindicato, diferentes organizaciones que confluyen en la sociedad civil:

Me parece que lo más concreto y sensato que se puede decir a propósito del Estado ético y de su cultura es lo siguiente: cada Estado es ético en cuanto una de sus funciones más importantes es 
la de elevar a la gran masa de la población a un determinado nivel cultural y moral, nivel (o tipo) que corresponde a las necesidades de desarrollo de las fuerzas productivas, y por consiguiente, a los intereses de las clases dominantes (Gramsci, 1980, p. 154)

La hegemonía viene a hacer el proceso mediante el cual la burguesía va a lograr, en el capitalismo, legitimarse como clase dominante a nivel político e ideológico-cultural, claro está, su origen se encuentra, como dice la cita anterior, en la base material, en las relaciones sociales que producen y generan una serie de contradicciones, reacciones y acciones que conllevan la necesidad de articular las diferencias en un interés particular que se va a revestir de neutralidad.

Según Gruppi (1976) el concepto de hegemonía en Gramsci se dirige hacia la articulación de la dominación y dirección. Es decir, contiene dos momentos, el primero en el que la clase burguesa y sus fracciones logran llegar a alianzas, acuerdos, consensos y a expandir su cultura a la clase trabajadora, masas populares y grupos oprimidos. El segundo, cuando la hegemonía se opera, por tanto, se ejerce políticamente:

La clase (o las clases) social en el poder dirige, al mismo tiempo que domina, gana para las soluciones que propone masas suficientes para construir la base de su propio poder, aunque los intereses reales de estas masas estén en oposición con sus soluciones. Todo ello se realiza mediante la política, el savoir-faire político de las clases dirigentes. Pero la política no basta: tiene que intervenir la ideología. Esta ideología que la clase dominante (capitalista por ejemplo) hace penetrar en las masas populares, en los obreros y en los campesinos por medio de la escuela y mediante la iglesia-jesencial en Italia!-, los medios de información, la instrucción militar, etc. (Gruppi, 1976, p. 45)

Es por ello que para Gramsci (1980), el Estado es un aparato de dominación y dirección, lo que denomina como hegemonía revestida de coerción. Donde la cultura de la burguesía, como clase hegemónica en el capitalismo, busca expandirse a toda la sociedad, en una forma de conquistar y dirigir la vida de las clases explotadas y sectores oprimidos, para con ello "soldar" su poder económico en lo político e ideológico. Entonces, las masas populares no cuentan con una concepción autónoma del mundo, un método de pensamiento crítico, ya que esto es controlado para que sea dirigido hacia determinados intereses que buscan "legitimar" la explotación y opresión a nivel general.

La fuerza de una clase en el campo cultural no consiste en permanecer en sus propios límites, sino sobre todo en su capacidad de expansión, en su facultad de conquistar el pueblo, de llegar a ser nacional: consiste, en suma, en la hegemonía (Gruppi, 1976, p.50).

La hegemonía se opera a través de una serie de aparatos, los que Althusser (1980) denomina aparatos ideológicos del Estado, como se vio en párrafos anteriores, el autor analiza esto para comprender cómo el Estado, además de represivo, busca reproducir la dominación del capital desde la ideología. Pero estos aparatos no se desarrollan como puramente ideológicos, ya que la coacción y coerción van a conformar parte de estos. No son dos formas excluyentes de intervenir en las contradicciones de la sociedad capitalista, sino una combinación que se confluye en este aparato, expresado en las políticas sociales.

La ideología es un elemento más por considerar en el proceso de reproducción social, se trata de una forma de consolidar una legitimidad de la violencia, de ocultar la opresión y dominación hacia la clase trabajadora, masas populares y grupos oprimidos que son socializados para que naturalicen la realidad de explotación y opresión en las que se colocan de acuerdo con la posición que se ocupe en el proceso productivo y reproductivo del capital (colocar lo falso como verdadero). Es decir, el Estado se encarga de organizar esa variedad de instituciones, organizaciones, aparatos, prácticas y discursos que socializan a las personas, según sus condiciones concretas sociomateriales, las cuales son estructuradas, se estructuran y son estructurantes a partir de la lucha de clases por la burguesía y sus fracciones para hegemonizar su dominación sobre la sociedad en general, organizadas desde el Estado a través del bloque en el poder. 
Según Althusser (1980), si se acepta en principio que la clase dominante ejerce el poder del Estado, ya sea en forma total o a través de alianzas, fracciones de clase o lo que se denomina desde Poulantzas (1972) bloque en el poder. El bloque en el poder "constituye una unidad contradictoria de clases y fracciones políticamente dominantes bajo la egida de la fracción hegemónica. La lucha de clases, la rivalidad de los intereses de esas fuerzas sociales está presente allí constantemente" (pp. 308-309). Es la clase burguesa que busca desde lo político consolidar las condiciones ideológicas-culturales necesarias para la acumulación ampliada del capital, cuya configuración del bloque en el poder implica una forma de Estado, siguiendo el mismo autor. Y por tanto buscan, el control de las contradicciones que emergen en el capitalismo gestadas en las luchas sociales y políticas, a través de su existencia como relaciones contradictorias anudadas en el aparato estatal, así, dispone por tanto del aparato (represivo) de Estado, podemos admitir que la misma clase dominante sea parte activa de los aparatos ideológicos de Estado, en la medida en que es en definitiva, es la ideología dominante la que se realiza, a través de sus contradicciones en los aparatos ideológicos del Estado (Althusser, 1980, p. 32).

Entonces, se puede decir que el Estado capitalista al concentrar y centralizar parte de las luchas sociales y interviene en la vida cotidiana de las personas desde un efecto universal, al constituir un punto de vista como legítimo, oficial, formal y que tiene un reconocimiento social, es decir una hegemonía (Gramsci, 1980), pero que no es neutral, sino emerge como dispositivo de control del capital ante las contradicciones que se producen y reproducen en el proceso de acumulación capitalista, que convergen y se sintetizan en las luchas sociales y políticas.

Es por ello, que el Estado capitalista, y por tanto, el bloque en el poder, a través de la política social, logra intervenir en la vida cotidiana, la regula, la organiza, reorganiza y las enmarca dentro de determinado ámbito económico, político e ideológico-cultural y así se inserta en estructuras mentales o las subjetividades de las personas, en una relación de acción y reacción. Se trata de la búsqueda de un "consentimiento", teniendo como base la sociedad burguesa. Esta función sería para Gramsci (1980) la hegemonía, es decir, del saber legítimo, lo oficial, formal y que se materializa en una ideología dominante a través de la sociedad civil. De esta manera, organizan las formas de vida, por medio de la reproducción de las relaciones de explotación y opresión desde las burocracias. Por tanto, implica a la vez una "sumisión" de lo individual para adscribirse en lo social, siempre mediado por las contradicciones del actuar del ser humano en las estructuras, estructuradas por la praxis y estructurantes de esa praxis.

Con esto el Estado capitalista, logra ser el garante, no neutral, de las relaciones conflictivas y contradictorias que se producen y reproducen en el capitalismo. Para el Trabajo Social lo planteado hasta aquí es fundamental, ya que significa comprender la forma en que actúa el espacio central desde donde interviene la profesión a través de las políticas sociales, como dispositivos de hegemonía en la búsqueda de mediar en las contradicciones del proceso de acumulación de capital. Este espacio en el que se desarrolla - no el único, pero si el principal - como profesión, es la forma política del capital, es decir de la relación social capitalista -la contradicción entre el capital y el trabajo (Holloway, 1980, 2017; Holloway y Pcciotto, 2017; Hirsch 2007 y 2017). Y por ello, donde la clase burguesa pugna por colocar sus intereses como universales, es decir la consolidación de un bloque de poder, a partir del cual una fracción de la burguesía construye su hegemonía, logrando que su interés particular sea asumido como el interés general, Por tanto:

Siendo el campo de intervención en el cual el trabajador social actúa un entero campo de mediaciones, en él se colocan las posibilidades tanto interventivas como intelectivas. Es ahí que el trabajador social construye su particularidad y su instrumentalidad (Guerra, 1995) e interviene de modo particular en las refracciones de la cuestión social. El trabajador social puede articular estas mediaciones potencializando fuerzas en presencia o simplemente mantenerse alienado en esta trama. (Guerra, 2015, p.38-39)

A partir de este último párrafo, se retoma un elemento más de la propuesta derivacionista para comprender el Estado, la incorporación de Hirsch, de Poulantzas y 
Grasmci y, en Holloway, su concepto de forma-proceso. Esto responde a la crítica de Jessop (2017), al considerar el Estado como polimormo y, por tanto, contradiciendo el postulado de que la acumulación del capital y sus crisis sea la variable orientadora de las limitaciones, contradicciones y posibilidades de la acción del estado.

La acumulación orientada al beneficio y regulada por el mercado es una entre varias orientaciones alternativas hacia el beneficio y, en suma, hay otros principios de organización social aparte de la acumulación diferencial. Qué principio sea el dominante puede influir en la forma y el impacto del poder estatal y es en sí mismo el resultado contingente del equilibrio de fuerzas puesto en marcha detrás de diferentes proyectos. Por eso, no existe garantía que el Estado moderno vaya a ser siempre (o llegue a ser alguna vez) principalmente capitalista en su naturaleza e, incluso cuando los representantes del capital y la racionalidad capitalista están profundamente integrados en su matriz organizativa, los proyectos de Estado normalmente tienen en cuenta otras exigencias funcionales y a la sociedad civil con el fin de promover la integración institucional y la cohesión social dentro de los límites territoriales del Estado.

Tanto Hirsch como Holloway, incorporan la discusión sobre la derivación a partir de las luchas sociales y políticas, y por tanto, el proceso de acumulación capitalista es histórico, comprendiendo el capital como relación contradictoria entre el capital y el trabajo. Siendo la propuesta una forma de analizar histórica y lógicamente la génesis y desarrollo del estado. Así para los autores, el Estado no estático, siendo la propuesta una base que debe integrar otros enfoques, tal y como lo plantea el primero, la "derivación del Estado no es, por ello, una teoría del Estado acabada; constituye empero, un punto de partida fundamental" (Hirsch, 2007, p.141). Desde esta premisa, Hirsch articula a su propuesta el aporte de Poulantzas, en cuanto al Estado en la sociedad capitalista como una relación social entre individuos, grupos y clases, por tanto la condensación material de las relaciones de fuerzas, pero es la forma particularizada de las relaciones sociales capitalistas, así formalmente separada y simultáneamente vinculada a la sociedad y las clases sociales. Es decir, una condición esencial para la implementación de la forma política del Estado, que implica a la vez, comprender que en el conflicto fundamental entre trabajo y el capital se expresan una heterogeneidad de formas de opresión (género, raza, nacionalidad, también en su relación destructiva con la naturaleza), concretadas en la organización de la sociedad burguesa, así:

Estas relaciones; sin embargo, se impregnan de la forma política del capitalismo en su aparición y modo de realización. Con ello, el Estado burgués es siempre al mismo tiempo un Estado capitalista, racista y patriarcal y la relación social de su aparato expresa, "regula" y concentra todas estas contraposiciones (Hirsh, 2007, p.149).

Siendo lo expuesto, base para el proceso de formación en Trabajo Social, al ayudar a comprender las heterogéneas formas de aparecer las manifestaciones de la cuestión social, condensadas en ese aparato estatal - en el sentido ampliado de Gramsci - a partir de la implementación de políticas sociales dirigidas a resolver las contradicciones del proceso de acumulación del capital, sin dejar que aparezcan como relaciones de clases, por ello, está implícito en la forma de "particularización" del estado burgués, que el aparato de estado necesariamente y en cualquier momento puede y debe colisionar no solo con la clase trabajadora o con partes de ella, sino también con los intereses de los capitales individuales y de grupos de capitales -intereses determinados por los requerimientos de la valorización (Hirsch, 2017, p.522).

Ante esto, Holloway (1980 y 2017) plantea su concepto de forma-proceso, es decir, el Estado es un proceso de formar relaciones sociales compatibles con la reproducción capitalista, que se enfrenta a luchas sociales y políticas que buscan conformar relaciones no mercantiles y, por tanto, anti la forma Estado capitalista. Colocando así, la discusión entre la relación dialéctica forma y contenido (Holloway y Picciotto 2017).

Retomando este último punto de Holloway y Picciotto (2017), lo expuesto por Hirsch $(2007,2017)$ y frente a la crítica de Jessop (2017), se plantea que la propuesta derivacionista no es una simple afirmación formalista logicista del origen y desarrollo del estado burgués, 
por el contrario, es un nivel abstracto de análisis, un punto de partida, según Evers (2003), para avanzar a un análisis de concreción histórica, en su caso de la forma política del Estado capitalista periférico, y a la vez implica retomar una heterogeneidad de mediaciones y categorías teóricas, como el de formación social ${ }^{16 .}$ Este autor, es incluido en el cronograma del curso Teoría del Estado y Políticas Públicas del 2009, específicamente para desarrollar parte de la segunda unidad, dirigida a estudiar algunos presupuestos teóricos sobre el Estado en la sociedad capitalista. Su propuesta implica utilizar un término que abarque la síntesis del análisis lógico e histórico, de la constitución del estado burgués:

Así, cuando se habla del análisis de las condiciones "constitutivas" de un estado, se trata de aplicar el conjunto de las precisiones lógicas (o sea la totalidad de aquellos elementos sistemáticos del modo de producción capitalista que posibilitan y exigen la separación de lo político en la forma del estado hacia dentro y hacia afuera) al análisis de una concreción histórica de fenómenos estatales (Evers, 2003, p.63).

Es decir, desde el método abstracto-concreto, mediado por la categoría formaciones sociales, por tanto "una teoría de la periferia capitalista solo puede darse en el primer nivel más general; por su contenido, es una teoría de las condiciones constitutivas de la forma burguesa del estado en formaciones económicamente subdesarrolladas" (p. 75).

Desde esta línea de comprensión de los aportes de la teoría derivacionistas, autores como Salama (2016), también la aplican en su explicación del proceso de desarrollo y forma de los estados de la periferia, buscando establecer un vínculo entre la derivación lógica, y la deducción histórica, por tanto, "el Estado, abstracción real (ver anexo 1), se mueve en lo concreto bajo la forma de regímenes políticos (y de gobiernos). Lo concreto que nosotros privilegiemos atañe a algunos países de América Latina” (p.133).

Por ello, son momentos distintos del conocer y captar en movimiento la realidad social, de desarrollo de los conceptos y concreción de los procesos históricos. Se trata del acercamiento del estudio a la totalidad social capitalista desde la dialéctica.

\section{Conclusiones}

Para el Trabajo Social, comprender el Estado capitalista desde el marxismo es fundamental para el desarrollo de su ejercicio profesional en la intervención de las heterogéneas manifestaciones de la cuestión social. Partir de la visión del aparato estatal con una arena de lucha política, donde la organización de la burguesía conlleva la desorganización de la clase trabajadora, masas populares y grupos oprimidos le permite acercarse a las distintas poblaciones por medio de las políticas sociales, teniendo claro el carácter contradictorio en el cual se gestan los derechos. Ello con el fin de, el Trabajo Social, saberse parte del proceso de controlar las contradicciones del capitalismo que convergen en luchas sociales, y que por tanto, el Estado es visto como factor de cohesión de la sociedad burguesa (Poultanzas, 1972, 1977 y 1983). Al ser un espacio de pugnas y controversias entre las burguesías, se convierte en un campo a partir del cual las distintas fracciones tratan de llegar a consensos y conciliaciones, en esa condensación material de fuerzas. Perpetuando las desigualdades propias del orden capitalista que buscan reproducir como condición inherente para su existencia, punto de partida para desarrollar una visión crítica del Estado, pero sin caer en ideas maniqueas, por el contrario aproximándose a la realidad desde la dialéctica.

Es una arena de lucha de clases, como elemento esencial de la forma Estado derivada del capital, y donde las burguesías buscan hegemonizar su poder, pero en el marco de una estructura que resguarda a nivel general el orden del capitalismo, es decir, el proceso de reproducción de la acumulación del capital. Y por ello, puede actuar aún en contra de los intereses inmediatos de las burguesías, para mantener las condiciones que le permiten su existencia, como lo plantean las tendencias derivacionistas, en el pensamiento de Altvater. Esto quiere decir, que puede asumir y asume intereses inmediatos y particulares de la clase trabajadora, masas populares y grupos oprimidos como una forma

16 Por formación social se comprende el proceso multilineal en un marco de tendencias generales de continuidad y discontinuidad del desarrollo desigual y combinado en el que se concreta el modo de producción capitalista en diferentes espacios y tiempos (Vitale, 2007) 
de rescatar el orden social propio de su existencia, siendo las políticas sociales prácticas surgidas de este proceso.

Se trata de un proceso contradictorio, ya que permite, producto de la lucha social, el acceso a la arena estatal de la clase trabajadora y sectores oprimidos para que coloquen sus demandas, pero esto significa una selección y contención de las acciones presentadas, como lo plantea Holloway (1994):

Siempre resulta difícil demarcar los límites de forma clara, a pesar de ello mantenemos que la lucha de clases, al entrar en contacto con la administración del Estado, siempre atraviesa un proceso de redefinición en términos de cómo el Estado ve a la sociedad, y-vista a través del Estado-la sociedad aparece como una masa de ciudadanos individuales (p.114)

Es decir, se convierte a la vez en un espacio de control social de las contradicciones que proliferan en el diario vivir de las personas abstraídas de sus condiciones sociomateriales y son igualadas por medio del Estado como ciudadanos y ciudadanas formalmente iguales y libres, que debido a este mismo proceso formalmente existente, también, pugnan sus demandas en el Estado, y con ello el proceso de contención y reproducción social del capital implica mediar y filtrar las "peticiones" ciudadanas.

Y aquí Poulantzas (1972 y 1983) permite avanzar en el tanto amplía el concepto o análisis que realizaba Marx y Engels en el Manifiesto Comunista donde colocaban al Estado moderno como la junta de gobierno que administra los intereses colectivos de toda la clase burguesa, es decir, un espacio de negociación, acuerdos, consensos y desacuerdos que conlleva a que el poder político no sea un automatismo.

El capital tiende a destruir sus propios fundamentos sociales, en la separación de lo económico y lo político (Hirsch, 2007 y 2017). Este, presionado por la competencia, se ve forzado a maximizar la utilización de los recursos independientemente de las consecuencias sociales y materiales que se desprendan (Altvater, 1976). Por ello, requiere de una forma especial de la realización de la existencia social del capital, paralelamente y, además de la competencia, como un momento esencial en el proceso de producción social del capital.

Es por ello que, las políticas sociales deben de contextualizarse en estas funciones generales del Estado, su expansión o contracción se relaciona con estas condiciones que desde la burguesía y sus fracciones pugnan y buscan reorientar según sea los intereses que estén en juego. Ante esto, los sectores dominados y oprimidos en el capitalismo pueden reaccionar de distinta forma, de acuerdo con la conciencia y condiciones objetivas y subjetivas que a la vez permitan o no la organización política de las masas populares, de la clase trabajadora y grupos oprimidos.

El Estado va a ser por tanto, la organización política del capital, en una condensación de instituciones y políticas heterogéneas que se consolidan como un aparato que logra converger, de forma contradictoria, la lucha de clases. Es la organización de la dominación en un espacio y tiempo determinado. Por ello, es el espacio central donde se dirimen las luchas sustantivas por el cambio social (Thwaites y Ouviña, 2012). Como lo plantea Engels (1975), en el Estado moderno, las luchas se concentran se dirigen hacia ese aparato que resguarda el poder de clase, ocultando la relación entre la lucha política y la base económica que condiciona a nivel general su funcionamiento.

Estado y poder son categorías inescindibles. Y no porque el poder no desborde los límites del Estado en sentido restringido -entendido como conjunto de aparatos-, o se desconozca que el poder también se expresa en la densa microfísica de relaciones que tan bien interpretara Foucault, y que previo a él supo teorizar Gramsci como dimensión "molecular" del poder. El punto que queremos destacar aquí es que, pese a todas las advertencias y admoniciones sobre su pérdida de relevancia, el Estado nacional "realmente existente" aún sigue siendo un nudo insoslayable en la articulación política (Thwaites y Ouviña, 2012, p. 54). 
Entonces, se puede decir que la praxis sobre las contradicciones es el producto de las demandas sociales que emergen de la lucha de clases, fundamentalmente, articuladas a otras formas de luchas sociales y políticas, de la forma en que esos conflictos, es decir la contradicción entre capital-trabajo son interpretados, gestionados y legitimados por los aparatos del Estado desde donde buscan actuar y consolidarse políticamente, ideológica y culturalmente la clase burguesa y sus fracciones en el capitalismo, por tanto es la búsqueda de la hegemonía (Gramsci, 1980). Las políticas sociales se van a conformar como parte de los dispositivos de intervención que desde el Estado se organizan en la búsqueda de contener el conflicto que emana de las contradicciones del capitalismo que pueden amenazar a la acumulación de capital.

Siendo el Trabajo Social una profesión donde su accionar es desde las políticas sociales, implica comprender la forma en que surgen, se desarrollan, cambian, contradicen y el avance o retroceso de la política pública en lo social. Esto permite generar o buscar alternativas, que si bien, como vemos son reformas, se pueden convertir a la vez en conquistas de la clase trabajadora, masas populares y grupos oprimidos, que de forma desigual y desde una competencia imperfecta pugnan por incidir en la toma decisiones para la búsqueda de su bienestar (en un aparato estatal que busca ser colonizado por las élites económicas).

Entonces en la relación Estado, cuestión social, políticas sociales y Trabajo Social. El Estado es visto como espacio de lucha social no neutral, la forma política del capital, la forma que reviste la explotación en el capitalismo. Y por tanto, las políticas sociales tienen una doble dimensión, son contradictoriamente asumidas por la clase trabajadora, masas populares y grupos oprimidos como conquistas de sus rebeliones y derechos legítimos, y por los capitalistas como una exigencia de las masas que contravienen la posibilidad del aumento de la tasa de ganancia, por tanto de la producción de valor.

Entonces, el Estado es un aparato, una forma de la relación social capitalista materializada, y un espacio de lucha social, donde las clases dominantes burguesas y sus fracciones buscan hegemonizar su poder pugnando por su interés de acumular la riqueza. Este se articula y estructura de acuerdo con el movimiento general de la acumulación de capital, lo que implica la resolución y contención de los conflictos que emergen de la desigualdad, opresión, explotación a partir de la producción y distribución de la riqueza en el capitalismo.

Por ello, para el Trabajo Social es el Estado capitalista un espacio contradictorio del ejercicio profesional, donde es instrumentalizado de forma contradictoria desde las políticas sociales que se dirigen, en nuestra época contemporánea a partir del proyecto neoliberal, hacia la re-focalización, mercantilización, precarización y privatización.

La profesión por medio de una praxis crítica, puede lograr avances en los procesos que busquen cierto bienestar de la clase trabajadora, masas populares y grupos oprimidos, al tener injerencia desde las políticas sociales en la vida cotidiana de las personas, puede ser parte de prácticas que generen condiciones para el acceso a los derechos, ya sea por la vía institucional del aparato estatal o a través de su vinculación en las luchas sociales. Para el conocimiento sobre la forma política del Estado y su funcionamiento, se hace medular en la formación, los elementos que brinda el marxismo. Siendo el Estado comprendido desde diferentes dimensiones que se combinan y relacionan de forma desigual para generar esa relación social de dominación y dirección compleja que rige como centro de poder político donde se toman las grandes decisiones.

Esas grandes decisiones que van a emerger como política sociales con las cuales el Trabajo Social está en una relación contradictoria, ya que desde un proyecto ético-político-crítico, cuyo fin es la transformación social buscando operar las políticas públicas para el bienestar de la población, pero a la vez se reproduce de manera general y particularizada las relaciones sociales capitalistas de explotación y opresión; y siendo ese espacio, una forma política de las relaciones sociales capitalistas, se inserta la profesión en una estructura que busca limitar su autonomía y por tanto, hegemonizar su instrumentalización para que a partir de la intervención se mantenga un "equilibrio" siempre desequilibrado de la sociedad capitalista. 
Esta complejidad debe ser comprendida, y es desde el marxismo con sus categorías centrales, mismas que se han ido transformando en el devenir histórico, es que se logra adentrar en las relaciones conflictivas y contradictorias bajo las cuales se desarrolla la profesión del Trabajo Social en relación con la forma Estado capitalista, este como relación social del capital organizada a nivel de lo político, garantizando el orden y las necesidades de la sociedad burguesa, en detrimento del desarrollo de las necesidades para la emancipación de la clase trabajadora, masas populares y grupos oprimidos, como lo plantea Guerra (2019), se hace necesario un proceso de formación que logre responder a los dilemas actuales.

A la vez, le permite acercarse a líneas de investigación para comprender el desarrollo de la profesión en el espacio estatal y las distintas formas de intervención del Estado a través de sus prácticas y discursos concretadas por medio de las políticas sociales, implementadas al nivel de la vida cotidiana de las personas, donde participan una heterogeneidad de actores y estructuras que se relacionan para generar un "modelo de atención" a las manifestaciones de la cuestión social. Siendo fundamental para el Trabajo Social, al ser la cuestión social su principal ámbito de acción.

Es decir, se considera, el marxismo para el estudio del Estado un fundamento teórico-crítico para explicar la praxis del Trabajo Social como parte de condiciones histórico-sociales, que le permite captar el movimiento contradictorio de la relación capital-trabajo, desenmascarando la forma fetichizada de aparecer y desarrollarse el Estado en la sociedad burguesa, el pseudoconcreto (Kosik, 1967). Se trata de una razón crítica-dialéctica para discutir las respuestas profesionales, tanto dentro como fuera del espacio estatal, partiendo de un análisis concreto en las diferentes situaciones y relaciones sociales en que se insertan como trabajadores y trabajadoras asalariadas. Y retomando el momento actual, donde se gesta un ataque brutal del capital a los derechos y conquistas de la clase trabajadora y diferentes sectores oprimidos, en el despojo acelerado de la posibilidad de la mínima subsistencia por la primacía del mercado en la voracidad del capital por mercantilizar todo bien material, servicio y relación social que le sea rentable para la acumulación, ha implicado un deterioro acelerado de las políticas sociales, mediante la implementación del proyecto neoliberal que determina una coyuntura adversa y produce nuevos desafíos para la profesión. Como lo plantea, Yazbek (2019):

Portanto, buscamos ultrapassar a análise do Serviço Social em si mesmo para situá-lo no contexto de relações sociais, mais amplas que o condicionam e lhe atribuem características particulares. Seu significado social, suas demandas, tarefas e atribuições devem ser identificados dentro da trama de relações que constituem as relações sociais capitalistas e, particularmente, nas respostas que a sociedade e o Estado constroem frente a questão social em suas múltiplas dimensões (matérias, espirituais, culturais, subjetivas, etc.). Nessa perspectiva, o assistente social desenvolve seu trabalho professional em situações sociais que afetam as condições de vida das "classes que vivem do trabalho” (Yazbek, 1999, p. 49)

Es decir, se hace necesario para el Trabajo Social un estudio de esa complejidad de la cual conforma parte, en la totalidad social capitalista, particularizando su significado en la atención que busca ser determinada (mediada por la hegemonía o directamente por la vía de la violencia represiva) a nivel estatal para incidir en la relación contradictoria capital-trabajo, fundamentalmente a partir de las políticas sociales, y por tanto la exposición teórica de los aportes del marxismo a la discusión del Estado nos acerca a captar esa totalidad social, en movimiento, estructurada, jerarquizada y desigualmente desarrollada en relación con sus partes, en la que la profesión es producto, ocupando un lugar en el proceso de reproducción de las relaciones sociales capitalistas, a partir de su praxis desde el espacio estatal de dominación de clase, es decir, en la forma política de la sociedad burguesa, siendo la teoría derivacionista, por ejemplo, necesaria y fundamental para lograr alcanzar este nivel de análisis. 


\section{Bibliografía}

Althusser, L. (1980). Ideología y aparatos ideológicos del Estado. En: La Filosofía como arma de la Revolución. Cuadernos de Pasado y Presente. Siglo XXI.

Altvater, E. (1976). Estado y capitalismo: notas sobre algunos problemas del intervencionismo del Estado, Cuadernos políticos, (9), 9-30.

Bonnet, A. (2016). El concepto de Estado capitalista en el pensamiento de Poulantzas. Herramienta web, 18.

Engels, F. (1970). Del socialismo utópico al socialismo científico. Editorial Progreso

Engels, F. (1975). Ludwin Feuerbach y el fin de la filosofía clásica alemana. Cuadernos de Pasado y Presente.

Engels, F. (2004). El origen de la familia, la propiedad privada y el Estado. Panamericana.

Engels, F. (2014). Anti-Duhring. La revolución de la ciencia por el señor EugenDurhring. Fundación Federico Engels.

Evers, T. (2003). El Estado en la periferia capitalista. Siglo XXI Editores

Gramsci, A. (1980). Notas sobre Maquiavelo, sobre la política y sobre el Estado Moderno. Nueva Visión.

Gruppi, L. (1976). El concepto de hegemonía en Gramsci. En Subirats, Joan, Colomer, Jaume y Rodríguez Aguilera de Prat. Revolución y Democracia en Gramsci. Fontamara.

Guerra, (2015). Trabajo Social: fundamentos y contemporaneidad. La Plata: Colegio de Trabajadores Sociales de la Provincia de Buenos Aires.
Guerra, Y. (2019). Consolidar Avanços, Superar Limites e Enfrentar Desafios: os Fundamentos de uma Formação Professional Crítica. Em Yolanda Guerra et al (org.). Serviço social e seus fundamentos: conhecimento e critica. Campinas: Editora Papel Social

Hirsch, J. (2007). Rasgos fundamentales de la teoría materialista del Estado. Ávalos Tenorio, Gerardo; Hirsch, Joachim, La política del capital. Universidad Autónoma Metropolitana

Hirsch, J. (2017). El aparato de estado y la reproducción social: elementos para una teoría del estado burgués. En Bonnet, Alberto y Piva, Adrián (comp.). Estado y capital. Herramienta.

Holloway, J y Picciotto, S. (2017). Hacia una teoría materialista del estado. En Bonnet, Alberto y Piva, Adrián (Comp.). Estado y capital. Herramienta.

Holloway, J. (1980). El Estado y la lucha cotidiana. Cuadernos Políticos, núm. 24, 7-27.

Holloway, J. (1994). Marxismo, Estado y Capital. La crisis como expresión del poder del trabajo. Tierra del Fuego.

Holloway, J. (2017). Un debate sobre la derivación del Estado. Una reflexión reminiscente. En Bonnet, Alberto y Piva, Adrián (comp.). Estado y capital. Herramienta.

Iamamoto, M. (2001). Servicio Social y división del trabajo. Cortez Editora

Jessop, B. (2017). El Estado. Pasado, presente y futuro. El más completo repaso a la teoría del Estado en los últimos treinta años. Catarata.

Kosík, Karel (1967). Dialéctica de lo concreto. Editorial Grijalbo S.A

Luxemburgo, R. (2001). Reforma o Revolución. Longseller. 
Mallardi, M. (2014). La intervención en Trabajo Social: Mediaciones entre las estrategias y elementos táctico-operativos en el ejercicio profesional. En Procesos de intervención en trabajo social: contribuciones al ejercicio profesional crítico, Manuel Mallardi (comp). Colegio de Asistentes Sociales o Trabajadores Sociales de la Provincia de Buenos Aires.

Marx, C y Engels, F. (2014). La ideología Alemana. Akal.

Marx, C. (2008). Contribución a la crítica de la economía política. Siglo XXI.

Marx, C. (2012). El Dieciocho Brumario de Luis Bonaparte. Alianza Editorial.

Miliband, M. (1978). El Estado en la sociedad capitalista. Siglo XXI.

Pastorini, A. (2000) ¿Quién mueve los hilos de las políticas sociales? Avances y límites de la categoría “concesión-conquista”. En: Borgianni, Elisabete y Montaño, Carlos (orgs.). La política social hoy. Cortez.

Poulantzas, N. (1972). Poder político y clases sociales en el estado capitalista. Siglo XXI.

Poulantzas, N. (1977). Sobre el Estado capitalista. Laia S.A.

Poulantzas, N. (1983). Estado, poder y socialismo. Siglo XXI.

Salama, P. (2016). El Estado y sus particularidades en los países emergentes latinoamericanos: un enfoque teórico a partir de la Escuela de la Derivación. En Artous, Antoine et al. Naturaleza y forma del Estado capitalista: análisis marxistas contemporáneos. Herramienta.
Thwaites, M y Ouviña H. (2012). La estatalidad latinoamericana revistada. Reflexiones e hipótesis alrededor del problema del poder político y las transiciones. En Thawaites, Mabel (ed). El Estado en América Latina: continuidades y rupturas. ARCIS.

Yazbek, M. (2019). Fundamentos históricos e teóricometodológicos e as tendências contemporâneas no Serviço Social. Em Yolanda Guerra et al (org.). Serviço social e seus fundamentos: conhecimento e critica. Campinas: Editora Papel Social.

Vitale, L. (2007). Modos de producción y formaciones sociales en América Latina. Rebelión. 